\title{
Da Química Verde À Verdura das Novas Tecnologias BIOTECNOLOGIA E NANOTECNOLOGIA
}

\author{
Adélio A. S. C. Machado *
}

\begin{abstract}
A Apresenta-se uma revisão dos primeiros resultados surgidos na literatura sobre a avaliação da verdura de processos da biotecnologia e da nanotecnologia por meio de métricas da Química Verde (QV) (mais precisamente, o Factor E), que revelam que as novas tecnologias podem ser mais deletérias para a Sustentabilidade do que a química, pelo que no desenvolvimento dos seus processos é necessário perseguir intencionalmente a benignidade ambiental. Para isso, aponta-se tentativamente como podem ser usados os Princípios da QV em cada uma das novas tecnologias.
\end{abstract}

O objectivo básico deste artigo é chamar a atenção para a importância que começa a ser dada à avaliação da verdura química dos processos usadas em biotecnologia e nanotecnologia para a preparação ou fabrico de compostos ou materiais. Mais precisamente, o texto discute a utilização recente $^{1}$ de métricas de massa da Química Verde (QV) [1], nomeadamente o Factor E, na aferição de processos destas novas tecnologias com o fito de enveredar pela sua implementação verde. Como a biotecnologia está já bem estabelecida, ao passo que a nanotecnologia está ainda numa fase de emersão, a perseguição deste objectivo tem aspectos diferenciados, embora em ambos os casos seja importante a adopção de métricas de verdura. Um segundo objectivo do artigo é evidenciar como estas diferenças se manifestam nas tentativas de procurar vias de implementação verde das duas tecnologias, por exemplo, nos modos de aplicação dos Princípios da $Q V^{2}$.

O texto começa por uma breve discussão do Factor $E$, a métrica que foi usada nas primeiras aplicações de métricas de QV às novas tecnologias, com o fim de evidenciar as limitações que a sua utilização alargada implica; continua depois por uma análise dos resultados obtidos com esta métrica de massa na avaliação da verdura

\footnotetext{
* Departamento de Química da Faculdade de Ciências da Universidade do Porto, R. Campo Alegre, 687 amachado@fc.up.pp
}

de algumas reacções ou processos biotecnológicos e nanotecnológicos, descritos recentemente na literatura; finalmente, inclui uma comparação dos valores de Factor $E$ encontrados nestas novas tecnologias com os da química e conclusões que se podem extrair da revisão realizada.

\section{FACTOR E}

O uso do Factor $E$, introduzido em 1992, por Sheldon [2], como métrica da QV $[1]^{3}$, tem contribuído para que a Indústria Química venha a focar cada vez mais atenção na importância da redução proactiva da produção de resíduos no fabrico industrial de produtos químicos [3].

No entanto, a comparação de valores do Factor $E$ referentes aos diversos sectores da Indústria Química, devido à elevada diferenciação destes, tem limitações - levanta o problema clássico de inadvertidamente se "comparar alhos com bugalhos". Por exemplo, as vias de síntese dos produtos químicos finos e de especialidade são quase sempre longas e elaboradas e é frequentemente requerida grande pureza do produto - por isso, os respectivos Factores $\mathrm{E}$ são muito mais elevados do que para os produtos químicos de base. Como o Factor $\mathrm{E}$ é uma grandeza relativa (massa de resíduos/massa de produto) ${ }^{4}$ e como as produções de produtos finos e de especialidade são muito menores que para os produtos de base, os seus valores podem ser enganadores quanto à quantidade total de resíduos produzidos nos dois casos ${ }^{5}$. Por maioria de razão, esta afirmação é válida para os casos das novas tecnologias, dada a sua ainda maior diferenciação, pelo que se deixa aqui um alerta.

Por outro lado, o cálculo do Factor E para produtos químicos tem excluído a água, porque a sua inclusão conduz a valores muito elevados, cuja comparação pode não ter grande significado global. Pelo contrário, em biotecnologia, o consumo de água pode atingir valores de nível ainda mais elevado, constituindo um aspecto crítico da verdura - e foi considerado na avaliação discutida a seguir.

\section{Problemas de Verdura da BIOTECNOLOGIA}

Recentemente [4,5], o Factor E começou a ser usado para aferição das consequências do fabrico de produtos farmacêuticos por via biotecnológica (por fermentação ou cultura celular), que, à escala industrial, envolve frequentemente a utilização de elevadas quantidades de consumíveis e grandes volumes de água, e a produção de quantidades substanciais de resíduos. Nesta actividade, o uso daquela e de outras métricas é importante para avaliar a verdura dos processos biotecnológicos de fabrico e promover o seu aumento. Aliás, este interesse parece natural já que, logo aquando da sua introdução [2], o Factor E revelou que as sínteses de compostos farmacêuticos, que frequentemen- 
te envolvem moléculas complexas, constituem uma das actividades da química onde a benignidade ambiental é menos cumprida - e a adopção da QV é mais premente.

Valores do Factor E em biotecnologia. O desenvolvimento de métricas adequadas à aferição da verdura dos processos de fabrico de produtos biotecnológicos está presentemente a ser estudado pela "Pharmaceutical Roundtable", que agrega o Green Chemistry Institute (GCI) da American Chemical Society (ACS) e várias empresas farmacêuticas e tem como objectivo a promoção da QV na indústria farmacêutica. Mais concretamente, um primeiro estudo sobre o Factor $\mathrm{E}$ nas actividades de biomanufactura na empresa Pfizer, visou a produção de proteínas terapêuticas, uma área da referida indústria presentemente em crescimento e cada vez mais importante $[4,5]^{6}$.

A biomanufactura de proteínas farmacêuticas ("produtos biofarmacêuticos"), quando comparada com o fabrico de pequenas moléculas por via química a partir do petróleo, parece atractiva quanto aos efeitos ambientais: as células ou micróbios que os produzem funcionam como reactores que usam quantidades relativamente pequenas de compostos químicos, geralmente benignos, para aporte de nutrientes, tamponação de $\mathrm{pH}$, etc., não requerendo solventes orgânicos em grande quantidade - mas como trabalham em meio aquoso, frequentemente muito diluído (com concentração do produto $<1 \%$ em massa), utilizam grandes volumes de água nos caldos de cultura ou fermentação. Adicionalmente, consomem também muita água noutras fases do processo, por exemplo, nas lavagens de equipamento, no isolamento e acabamento final do produto, etc. Nesta fase de purificação são igualmente requeridos auxiliares consumíveis (filtros, resinas cromatográficas, tubagens, solventes, etc.). Em certos casos, quando é necessário realizar a conversão do produto em formas bioactivas e na obtenção do produto farmacêutico formulado, podem ocorrer dispêndios apreciáveis de água e materiais consumíveis. Assim, na avaliação da verdura da produção biotecnológica tem de se atender a todos estes consumos, sendo importante considerar a água despendida.

Os resultados obtidos no cálculo dos Factor $E$ e requisitos de reagentes para a preparação de dois produtos biofarmacêuticos, um produzido por cultura celular (anticorpo monoclonal) e o outro por fermentação bacteriana (uma proteína de tamanho médio) [4,5], são apresentados na Tabela 1.

Tabela 1 Factor E e consumo de reagentes e materiais no biofabrico de produtos

\begin{tabular}{|c|c|c|}
\hline & $\begin{array}{c}\text { Cultura celular } \\
\text { (anticorpo monoclonal) } \\
(\mathrm{kg} / \mathrm{kg} \text { de produto) }\end{array}$ & $\begin{array}{c}\text { Fermentação microbiana (E. coli) } \\
\text { (proteína não-glicosilada de tamanho médio) } \\
\text { (kg//g de produto) }\end{array}$ \\
\hline Factor E & 7.600 & 15.500 \\
\hline Água & 7.000 & 15.000 \\
\hline Sais inorgânicos/tampões & 600 & 400 \\
\hline Solventes orgânicos & $8 c$ & $100^{\text {d }}$ \\
\hline Consumíveis & 4 & 20 \\
\hline
\end{tabular}

a) Com base em dados de produção da empresa Pfizer (valores respigados de [5])

b) Saem do processo nas águas residuais

c) Principalmente álcoois

d) Incluindo alguns perigosos
Os valores do Factor E são muito elevados (7.600 e 15.500, respectivamente) porque se incluiu a água no cálculo; no entanto, quando esta é excluída, os valores diminuem mas continuam bastante elevados, respectivamente da ordem de 600 e 500. Para comparação, o estudo considerou o que se passava na produção de um conjunto de dezanove moléculas de interesse farmacêutico de pequeno tamanho sintetizadas também na Pfizer, para as quais os resultados médios foram: Factor E, 174 kg/kg de produto ${ }^{7}$; solventes orgânicos e água, cerca de 100 e 50 kg/kg de produto, respectivamente. No entanto, uma análise preliminar do processo de fabrico do anticorpo monoclonal com vista à sua optimização ambiental revelou que a carga ambiental, avaliada pelo Factor $\mathrm{E}$, poderá ser reduzida a cerca de metade [5].
Em suma, o fabrico de produtos biofarmacêuticos é realizado presentemente com valores de Factor $\mathrm{E}$, água excluída, várias vezes superiores ao das moléculas mais pequenas obtidas por síntese química - se se incluir a água, os valores relativos aumentam muito mais. $O$ estudo põe assim em causa a ideia feita de que os produtos obtidos por "síntese biológica" são naturalmente verdes por quase não envolverem reagentes, nomea-

\section{Quadro 1 \\ Inovações tecnológicas a explorar pela biotecnologia com vista a obter verdura \\ Tecnologia química \\ Uso de reactores descartáveis em vez de tanques de fermentação de aço inox (poupam água de lavagem, esterilização, etc., mas constituem resíduos sólidos) \\ Desenvolvimento de reactores de fluxo contínuo de pequena dimensão

$$
\text { Adopção de separações não cromatográficas }
$$$$
\text { Biologia de base }
$$$$
\text { Síntese sem a presença de células }
$$

Desenvolvimento de novas plantas geneticamente modificadas para produzir compostos 
Um exemplo optimista - o caso da Genentech. Há já informação que confirma que quando o problema do consumo de água pela indústria farmacêutica é atacado com voluntarismo, os resultados podem ser eficazes e rápidos. Por exemplo, a empresa Genentech [6], em 2004, decidiu fixar como meta de poupança de água, a atingir em 2010, o valor de 10\% (baixar o consumo de água por unidade de produto produzido de 886 para 797 $\mathrm{m}^{3} / \mathrm{kg}$ ). Como mostra a Fig. 1, esta meta foi ultrapassada (melhor, infrapassada!) logo em 2005; e o volume de água gasto em 2007 por unidade de produto obtido decresceu $31 \%$ relativamente a $2004^{8}$. Em consequência, a empresa tem presentemente uma posição algo mais optimista sobre a poupança de água do que quando começou a atacar o problema. (ii) projectos especificamente dirigidos à conservação da água (por exemplo, substituição de sistemas de refrigeração que usam bombas de vácuo por sistemas em circuito fechado) e respectiva recuperação e reciclagem (por exemplo, redu-
No Quadro 2 sem preocupações de exaustividade, exemplifica-se a relevância de alguns dos Doze Princípios da QV para o cumprimento de objectivos pró-ambientais na síntese biotecnológica de produtos biofarmacêuticos, conforme sugerido pela discussão anterior.

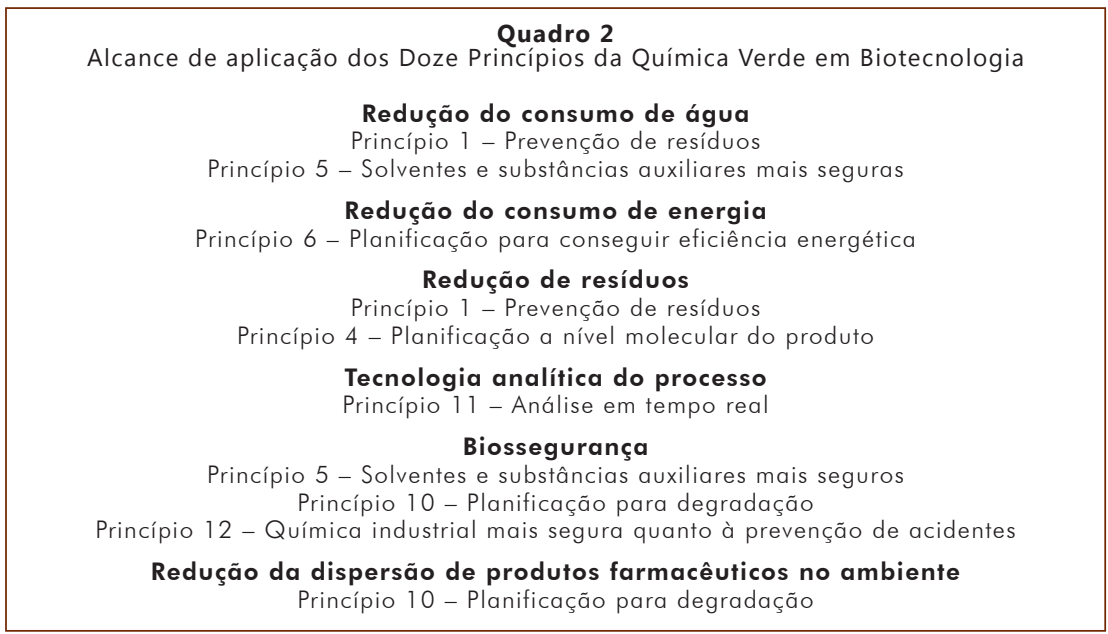

\section{EVOLUÇÃO DO CONSUMO GLOBAL DE ÁGUA DA MULTINACIONAL GENENTECH}

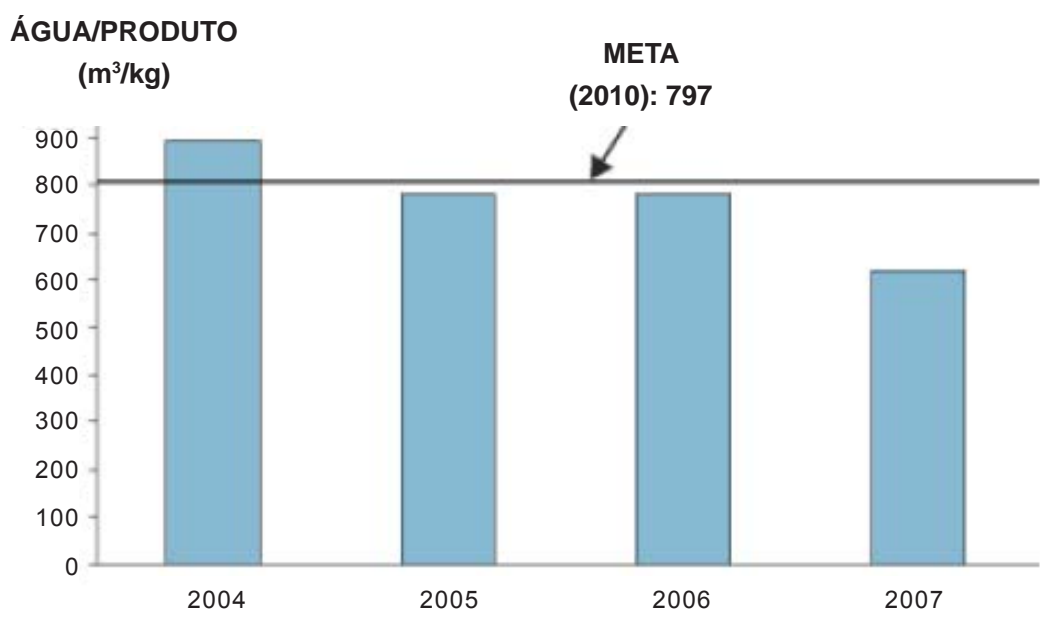

(BASE: 886)

Figura 1 O êxito do programa de poupança de água da multinacional Genentech [6]

A poupança foi conseguida por diversas vias, por exemplo:

(i) aumento da eficiência do uso da água nas operações de fabrico, incluído num esforço contínuo de melhoria dos processos industriais - os processos biotecnológicos são, em geral, complexos e, por exemplo, pequenas variações de condições podem provocar diferenças substanciais de rendimento (ou até a obtenção de partidas impróprias que têm de ser descartados), pelo que um bom controlo permite aumento de eficácia, incluindo no consumo de água; ção da percentagem de água rejeitada durante uma purificação por osmose invertida).

\section{Discussão:}

As considerações anteriores mostram que a luta pela verdura da indústria farmacêutica se põe tanto no campo da síntese biotecnológica como no campo da química - também os processos do primeiro tipo devem ser analisados por meio dos Princípios da QV e de métricas adequadas, para poderem ser optimizados quanto aos efeitos ambientais.

\section{Problemas de Verdura da Nanotecnologia}

O desenvolvimento corrente da nanotecnologia, que integra a investigação de uma enorme variedade de aplicações potenciais de nanopartículas na criação de novos materiais, tem vindo a ser acompanhado por uma crescente preocupação quanto às suas consequências ambientais e para a saúde humana. Neste contexto, está em emersão o campo da nanotecnologia verde, que envolve a aplicação conjunta dos princípios da QV e da Engenharia Verde na síntese de novos nanomateriais com uma atitude proactiva de eliminar os seus efeitos deletérios [7-9]. A necessidade de passar a utilizar métricas de QV para avaliar a benignidade da nanociência e nanotecnologia começou recentemente a ser apontada $[7,10]$ e em 2008 foram publicados dois estudos sobre a aferição da verdura de algumas nanossínteses por cálculo de métricas de massa (Factor $E$ [11] e outras análogas [12]), cujos resultados serão revistos a seguir.

\section{Valores de Factor E em nanotecno-} logia. Na Ref. [11] foram apresentados cálculos do Factor $E$ para quatro nanomateriais (nanotubos de carbono, fulerenos, dióxido de titânio e nanopartículas de ouro, neste último caso referentes a seis processos de preparação distintos). Os valores do 
Factor E foram calculados repetitivamente incluindo e excluindo os materiais gastos na fase final de separação e purificação, no caso de esta última fazer parte do processo (os resultados finais são respigados na Tabela 2). Os valores foram obtidos a partir de preparações à escala laboratorial, seguindo protocolos precários, já que a nanotecnologia está ainda na sua infância e em evolução rápida, com os praticantes interessados em obter novos produtos por novos processos, sem prestarem grande atenção à obtenção de verdura - por isso, provavelmente, protocolos não optimizados proactivamente quanto a esta. No que respeita às nanopartículas de ouro, os diversos processos conduzem a produtos diferentes (quanto a tamanho, dispersão, pureza, etc.) e as duas preparações, por autores diferentes, pelo mesmo processo (estabilização por fosfina), conduziram a valores muito diferentes do Factor E. Em consequência da falta de controlo dos variados factores em jogo nas preparações, os valores desta métrica de verdura estão provavelmente afectados por incertezas elevadas (e elas próprias incertas!), não sendo lícito usá-los em comparações rigorosas. Embora valham apenas como ordem de grandeza, a discussão dos valores do Factor $\mathrm{E}$ conduz a conclusões interessantes.

Tabela 2 Factor E para exemplos de nanossínteses de vários nanomateriais (adaptada de [11])

\begin{tabular}{|c|c|}
\hline Processo & Factor $\mathrm{E}^{\mathrm{a}}$ \\
\hline \multicolumn{2}{|c|}{ Nanotubos de carbono } \\
\hline Deposição química de vapor & $170(22)$ \\
\hline \multicolumn{2}{|c|}{ Fulerenos $\left(C_{60}\right)$} \\
\hline Chama benzeno-oxigénio & $950(950)$ \\
\hline \multicolumn{2}{|c|}{ Dióxido de titânio $\left(\mathrm{TiO}_{2}\right)$} \\
\hline Hidrólise e calcinação & $17.800(44)$ \\
\hline \multicolumn{2}{|c|}{ Nanopartículas de ouro } \\
\hline Estabilização por fosfinas & $7.200(1.760)$ \\
\hline Estabilização por fosfinas & $19.200(200)$ \\
\hline Estabilização por tiol (líquido-líquido) & $3.320(340)$ \\
\hline $\begin{array}{l}\text { Estabilização por líquidos iónicos } \\
\text { funcionalizados com tiol }\end{array}$ & $99.400(96.400)$ \\
\hline Absorpção por alfafa & $-{ }^{b}(163)$ \\
\hline Amido-glucose & $-\mathrm{b}(29.600)$ \\
\hline
\end{tabular}

a)Valor após operações de separação/purificação (entre parêntesis, valor antes da separação/purificação) b) Não foi realizada separação ou purificação

A Tabela 2 mostra valores de Factor $\mathrm{E}$ numa gama muito ampla (com largura da ordem de grandeza de cinco décadas para os valores entre parêntesis, em que se omite a purificação), atingindo níveis muito superiores aos referentes aos produtos químicos e farmacêuticos [2] - o factor $E$ atinge valores de dezenas de milhar e mesmo, num dos casos, quase uma centena de milhar. Na maioria dos casos, mas não em todos, a purificação envolve quantidades elevadas de solventes (lavagens) que são responsáveis por grandes acréscimos do Factor $\mathrm{E}$ (até centenas de vezes). Para as nanopartículas de ouro, os valores do Factor E referentes aos diversos processos de preparação apresentam também grandes disparidades.

Assim, a Tabela 2 evidencia alguns factos que merecem realce quanto se considera a implementação da nanotecnologia verde:

(i) certas nanossínteses são ambientalmente problemáticas - produzem quantidades brutais de resíduos (Factor E muito elevado);

(ii) outras nem tanto (Factor $E$ muito mais baixo), valendo a pena considerá-las para serem submetidas a optimização da verdura na fase de escalamento (visando o abaixamento do Factor E e não só); finalmente, (iii) a fase de purificação do nanocomposto provoca frequentemente uma grande deterioração da verdura (aumento do Factor E), sendo ideal divisar processos que originem directamente o produto, sem necessidade de purificação, ou que usem técnicas de purificação pouco ávidas de solventes.

Identicamente à $\mathrm{QV}$, onde é preciso inventar vias favoráveis de síntese verde que cumpram simultaneamente todos os Doze Princípios, a prática da nanotecnologia requer o cumprimento sistémico deste mesmo objectivo. Por exemplo, o processo de obtenção de nanopartículas de ouro com base na glucose (redutor) e no amido (estabilizador) [13], foi proposto como uma "síntese completamente verde" pelos seus autores (ver título de [14]), com base na benignidade dos dois reagentes usados quanto a toxicidade; no entanto, envolve uma razão de quantidades amido:metal tão elevada que o Factor E é da ordem de dezenas de milhar (Tabela 2).

A Ref. [12] relata o desenvolvimento de um método para a avaliação relativa da verdura de processos de síntese de nanomateriais, baseado numa bateria alargada de métricas de sustentabilidade [15], incluindo a avaliação comparativa de três processos de fabrico de nanopartículas de sílica, à escala laboratorial, um deles por via húmida (sol-gel) e os outros dois em reactores de chama, a partir de dois precursores diferentes (indicados na Tabela 3).

O artigo inclui valores da Economia Atómica (EA) e de métricas de verdura do tipo do Factor $E$ (massas de "Materiais usados" e "Resíduos gerados", ambas por unidade de massa de produto) para os três processos de fabrico (ver Tabela 3). Estes resultados evidenciam uma situação semelhante à descrita no caso anterior [11]: os valores das métricas detectam verdura pobre e apresentam uma dispersão da ordem de duas décadas entre os três processos de nanossíntese. Os resultados na Tabela 3 sugerem que o terceiro processo (que usa HMDSO como reagente de partida) é melhor que os outros dois, o que é confirmado pelo conjunto global de métricas usadas no 
método de avaliação proposto [12], o qual inclui métricas de engenharia verde [15] a par das de QV. gumas linhas de aplicação conjunta de grupos de Princípios da QV à nanotecnologia, evidenciando os que são mais importantes em diversos aspectos em jogo no design de nanoprodutos verdes e dos processos para a sua preparação.

Tabela 3 Métricas para três nanossínteses de nanopartículas de sílica (Valores respigados de [12])

\begin{tabular}{|c|c|c|c|}
\hline Processo de nanosíntese & Economia atómica (\%) & $\begin{array}{c}\text { Materiais usados } \\
\text { (g/g de produto) }\end{array}$ & $\begin{array}{c}\text { Resíduos produzidos } \\
\text { (g/g de produto) }\end{array}$ \\
\hline Sol-gel & 2,05 & 738 & 1004 \\
\hline Chama (TEOS) & 111 & 105 \\
\hline Chama (HMDSO) & 0,95 & 4,49 & 12,9 \\
\hline
\end{tabular}

a)TEOS = Tetraetilortossilicato

b) $\mathrm{HMDSO}=$ Hexametildissiloxano

\section{Discussão:}

Estes resultados sugerem que a qualificação de verde, que vem sendo atribuída recentemente a várias nanossínteses com base no simples uso de reagentes benignos ou de origem biológica [13,14,16-19], pode ser enganadora $^{9}$, e que o uso de métricas de massa na análise dos processos de nanossíntese pode clarificar muito melhor o grau em que a verdura é cumprida.

Por outro lado, não há ainda qualquer estudo sobre métricas dos efeitos toxicológicos e ecotoxicológicos dos nanocompostos, nem será de esperar que as possa haver a curto prazo, dadas as dificuldades de desenvolver o campo da nanotoxicologia [20,21], que começam na complexidade da caracterização física dos nanomateriais para realizar testes toxicológicos [22] e continuam, por exemplo, na toxicocinética peculiar que resulta das elevadas razões "área superficial/volume" das partículas $[20]^{10}$.

As lacunas de conhecimento nos domínios quer da toxicidade quer da exposição impedem que para já se possam realizar avaliações de risco de confiança [20 ${ }^{11}$.

As dificuldades de lidar com os efeitos ambientais da nanotecnologia estão presentemente a ser considerados com interesse crescente ( $p$. ex. [23-25]), num contexto mais alargado de procurar desenvolver este ramo emergente da tecnologia na forma de nanotecnologia verde [7,9].

Neste âmbito, a Fig. 2, construída a partir das discussões em [7-9], sugere al-
DESIGN DE NANOMATERIAIS PARA...

... SEGURANÇA (Princípios 4 e 12)

DETERMINAR OS IMPACTOS BIOLÓGICOS DO TAMANHO, ÁREA SUPERFICIAL E FUNCIONALIDADE SUPERFICIAL DOS NANOMATERIAIS

UTILIZAR O CONHECIMENTO PARA O DESIGN DE NANOMATERIAIS MAIS SEGUROS COM AS PROPRIEDADES FÍSICAS REQUERIDAS

$\nabla$

NÃO INCORPORAR ELEMENTOS TÓXICOS NA COMPOSIÇÃO DE NANOMATERIAIS

... REDUÇÃO DO IMPACTO AMBIENTAL (Princípios 7 e 10)

DETERMINAR O TRANSPORTE, DESTINO E DEGRADAÇÃO DOS NANOMATERIAIS NO AMBIENTE

$\nabla$

UTILIZAR O CONHECIMENTO PARA O DESIGN DE NANOMATERIAIS QUE SE DEGRADEM A PRODUTOS OU SUBUNIDADES INÓCUOS

$\nabla$

NÃO INCORPORAR ELEMENTOS PERIGOSOS NA COMPOSIÇÃO DE NANOMATERIAIS

PROCURAR USAR MATÉRIAS-PRIMAS INÓCUOS DE ORIGEM BIOLÓGICA

... REDUÇÃO DE RESÍDUOS (Princípios 1, 5 e 8)

ELIMINAR PURIFICAÇÕES QUE USEM INTENSIVAMENTE SOLVENTES MEDIANTE UILIZAÇÃO DE SÍNTESES NANOSSELECTIVAS PARA OBTER PUREZA E MONODISPERSIVIDADE

DESENVOLVER NOVOS MÉTODOS DE PURIFICAÇÃO QUE MINIMIZEM O USO DE SOLVENTES (EX. NANOFILTRAÇÃO)

$\nabla$

UTILIZAR PROCESSOS ASCENDENTES ("BOTTOM-UP”) PARA AUMENTAR A EFICIÊNCIA DE MATERIAIS E ELIMINAR ETAPAS

... SEGURANÇA DO PROCESSO (Princípios 3, 5, 7 e 12)

CONCEBER E DESENVOLVER SÍNTESES ESCALADAS QUE UTILIZEM REAGENTES E SOLVENTES MAIS BENIGNOS QUE AS LABORATORIAIS

UTILIZAR MATÉRIAS-PRIMAS MAIS BENIGNAS, SE POSSÍVEL DERIVADAS DE RECURSOS RENOVÁVEIS

$\nabla$

IDENTIFICAR SUBSTITUTOS PARA OS REAGENTES TÓXICOS E PIROFÓRICOS

... EFICIÊNCIA DE MATERIAIS (Princípios 2, 5, 9 e 11)

DESENVOLVER NOVAS ESTRATÉGIAS DE SÍNTESE COMPACTAS

$\nabla$

OPTIMIZAR A INCORPORAÇÃO DE REAGENTES DE BASE NOS PRODUTOS ATRAVÉS DE PROCESSOS ASCENDENTES ("BOTTOM-UP”)

USAR MEIOS DE REACÇÃO ALTERNATIVOS E CATÁLISE PARA AUMENTAR A SELECTIVIDADE $\nabla$

USAR MONITORIZAÇÃO EM TEMPO REAL PARA REALIZAR O CONTROLO DO PROCESSO EM SÍNTESES COMPLEXAS DE NANOMATERIAIS

... EFICIÊNCIA DE ENERGIA (Princípios 6, 9 e 11)

PROCURAR VIAS DE SÍNTESE EFICIENTES REALIZÁVEIS À TEMPERATURA AMBIENTE

$\nabla$

UTILIZAR METODOS DE MONTAGEM NÃO-COVALENTE E ASCENDENTES (“BOTTOM-UP”) À TEMPERATURA AMBIENTE

USAR MONITORIZAÇÃO EM TEMPO REAL PARA OPTIMIZAR AS REACÇÕES QUÍMICAS E MINIMIZAR OS CUSTOS DE ENERGIA

Figura 2 Uso dos Princípios da QV na concepção e fabrico de novos nanomateriais segundo a postura do "Design para..." 


\section{FActor e EM Química, Biotecnologia e Nanotecnologia}

Esta recensão dos primeiros estudos sobre métricas de massa da QV referentes a sínteses de materiais por vias biotecnológica e nanotecnológica mostra que o problema de obter verdura no fabrico de produtos das novas tecnologias é tão agudo como nas sínteses da química tradicional - na realidade, os exemplos apresentados constituem situações piores que as tipicamente encontradas para a síntese química de compostos farmacêuticos, para os quais o Factor $E$ atinge valores da ordem de 100 ou mesmo superiores [2]. Na Tabela 4 completa-se a tabela de valores típicos de Factor E, primitivamente apresentada por Sheldon [2] para diversos tipos de produtos químicos, com valores sugeridos pela discussão anterior para produtos biofarmacêuticos e nanotecnológicos. A tabela sugere que a biotecnologia e a nanotecnologia incluem processos que podem ser muito menos verdes que os da química, embora em face das limitações do Factor $E$ discutidas atrás, esta afirmação tenha de ser encarada com cautela - nomeadamente, não pode ser considerada geral.

Tabela 4 Factor E para diversos tipos de produtos

\begin{tabular}{|c|c|}
\hline Tipo & Factor $\mathrm{E}$ \\
\hline Produtos de base & $<1-5$ \\
\hline Produtos finos & $5-50$ \\
\hline Produtos farmacêuticos & $25->100$ \\
\hline Produtos biofarmacêuticos & $7.000-15.000^{\circ}$ \\
\hline Nanomateriais & $100-100.000$ \\
\hline
\end{tabular}

a) Este intervalo é uma falsa gama de valores, já que é definido pelos dois únicos valores existentes (ver texto)

\section{Conclusões}

A análise apresentada não pretende por em cheque as novas tecnologias, mas apenas vincar que devem ser implementadas com atenção intencional à verdura de materiais e processos, para evitar a repetição do que sucedeu com o desenvolvimento da química - em que, ao longo do século $X X$, se prepararam à escala industrial e se puseram em utilização muitos compostos deletérios para a saúde humana e ecológica, parte dos quais têm vindo a ser retirados do merca- do após reconhecimento dos seus efeitos nocivos, muito tempo depois da sua introdução. Na prática, fundamentalmente, a presente revisão pretende ser uma chamada de atenção para a necessidade de os praticantes da biotecnologia e da nanotecnologia passarem a adoptar a postura da QV tão precocemente quanto possível, logo no estudo laboratorial das vias de síntese de materiais que desenvolverem, de modo a aplicar os Doze Princípios da QV em conjunto, de forma sistémica. Só assim conseguirão privilegiar proactivamente a selecção e optimização dos processos para obter verdura, identificando os que nem utilizem reagentes nem produzam resíduos perigosos, apresentem elevada produtividade atómica [1], consumam o mínimo de energia, ${ }^{12}$ etc.

Mais concretamente, os estudos que foram aqui descritos mostram a necessidade de incrementar a avaliação quantitativa da verdura mediante métricas na prática de novas tecnologias, tal como na química - embora as métricas possam ser imprecisas na avaliação de verdura, permitem evidenciar a sua falta em situações concretas.

Finalmente, em face da Tabela 4, os químicos incautos poderão afirmar que, afinal, as novas tecnologias são menos verdes que a química - no entanto, a falta de verdura de materiais produzidos pela biotecnologia e nanotecnologia não pode servir para justificar uma atitude de auto-complacência por parte dos químicos quanto à perseguição da verdura na prática da própria química.

Por outro lado, os químicos podem aumentar legitimamente a sua autoestima quando tomam consciência que, conforme a discussão anterior mostra, a QV tem uma importância muito lata em tecnologia, que transcende em muito o campo da Química Industrial - o que resulta de a química desempenhar um papel fundamental em toda a tecnologia (e, em particular, uma papel fulcral na biotecnologia e na nanotecnologia).

\section{Notas}

1 Para melhor sistematização da bibliografia, as referências bibliográficas específi- cas foram diferidas para as respectivas secções no corpo principal do texto.

2 Para os enunciados dos Princípios da QV e respectiva bibliografia no $B S P$ Química, ver [26,27].

3 O Factor E é uma medida de produtividade atómica condicional, isto é, baseada nas condições e circunstâncias específicas usada num processo, sendo portanto de preferir à economia atómica (EA), que é uma métrica de produtividade atómica intrínseca, que mede até que ponto um processo pode ser inerentemente eficiente, se todas as condições forem perfeitas [11]. Por isso, para avaliar processos em condições reais é preferível usar o Factor $\mathrm{E}$, sempre que possível.

4 Se não for possível saber a massa de resíduos, o Factor $\mathrm{E}$ pode ser calculado pela razão (massa de reagentes estequiométricos e auxiliares - massa de produto)/massa de produto.

5 Além disso, como o factor $E$ envolve só a quantidade de resíduos formados, não a sua natureza, não é uma medida rigorosa do impacto ambiental da síntese ou processo de fabrico (nomeadamente, não atende à toxicidade dos resíduos).

6 As proteínas terapêuticas são de dois tipos: glicoproteínas (na forma de anticorpos monoclonais), produzidas por culturas de células de mamíferos (cerca de $60 \%$ do mercado); e proteínas não-glicosiladas, produzidas por fermentação microbiana de $E$. coli geneticamente modificadas ou outros micróbios (restantes 40\%) [5].

7 Se se descontar a água, os valores são da mesma ordem de grandeza dos primitivamente referidos por Sheldon [2] para este tipo de compostos (Factor E na gama 20 a $>100 \mathrm{~kg} / \mathrm{kg}$ produto).

8 No entanto, a quantidade total de água consumida anualmente pela empresa tem aumentado devido aos aumentos de produção anual.

9 Esta situação configura mais um caso de "falsa" QV conforme discutido em [27].

10 Esta situação é natural, já que o interesse na nanotecnologia provém da habilidade de embutir novas propriedades e capacidades a materiais com base no tamanho e geometria das unidades que os constituem, o que complementa a via tradicional de controlar as propriedades dos materiais através da sua composição química: a "inovação benéfica" nas propriedades úteis arrasta consigo 
e inclui a "inovação maléfica" das propriedades responsáveis pelos efeitos toxicológicos!

${ }^{11}$ Foi já realizada uma avaliação de risco comparativa de vários nanomateriais [28] num contexto restrito (o da indústria de seguros) mas refere-se apenas ao processo de fabrico, excluindo os impactos e riscos dos próprios materiais.

12 Por exemplo, um estudo recente [29] mostrou que os nanomateriais de carbono são muito intensivos em energia (da ordem de 2-100 vezes mais que o alumínio, conforme o material e o método de síntese).

\section{REFERÊNCIAS}

[1] A. A. S. C. Machado, "Métricas da Química Verde - A Produtividade Atómica”, BSP Química 107 (2007) 47-55.

[2] R. A. Sheldon, "Organic Synthesis Past, Present and Future", Chem. Ind. (London) (1992) 903-906.

[3] R. A. Sheldon, "The E Factor: Fifteen Years On”, Green Chem. 9 (2007) 1273-1283.

[4] S. V. Ho, J. K. McLaughlin, A. C. Espenschied e J. F. Bouressa, "Green Technology Assessment of Therapeutic Protein Manufacture", $11^{\text {th }}$ Annual Green Chemistry and Engineering Conference (2007), Abstract 218 (em http://acs.confex.com/acs/green07/ techprogram/P41555.HTM, acedido em 2009.02.04)

[5] S. K. Ritter, "Toward Greener Therapeutic Proteins", C\&EN 85 (4, Jan 28) (2008) 63-66.

[6] http://www.gene.com/gene/about/ environmental/using/water.html (acedido em 2009.02.04).

[7] J. A. Dahl, B. L.S. Maddux e J. E. Huthison, "Toward Greener Nanosynthesis", Chem. Rev. 107 (2007) 2228-2269.

[8] J. E. Hutchison, "Greener Nanoscience: A Proactive Approach to Advancing Applications and Reducing Implications of Nanotechnology", ACS Nano 2 (2008) 395-402.
[9] B. Karn, "The Road to Green Nanotechnology”, J. Ind. Ecol. 12 (2008) 263-266 .

[10] M. A. Albrecht, C. W. Evans e C. L. Raston, "Green Chemistry and the Health Implications of Nanoparticles", Green Chem. 8 (2006) 417-432.

[11] M. J. Eckelman, J. B. Zimmerman e P. T. Anastas, "Toward Green Nano - EFactor Analysis of Several Nanomaterial Syntheses", J. Ind. Ecol. 12 (2008) 316-328.

[12] S. Naidu, R. Sawhney e X. Li, "A Methodoly for Evaluation and Selection of Nanoparticle Manufacturing Processes Based on Sustainable Metrics", Environ. Sci. Technol. 42 (2008) 6697-6702.

[13] P. Raveendran, J. Fu e S. L. Wallen, "A Simple and "Green" Method for the Synthesis of $\mathrm{Au}, \mathrm{Ag}$ and $\mathrm{Au}-\mathrm{Ag}$ Alloy Nanoparticles", Green Chem. 8 (2006) 34-38.

[14] P. Raveendran, J. Fu e S. L. Wallen, "Completely "Green" Synthesis and Stabilization of Metal Nanoparticles", J. Am. Chem. Soc. 125 (2003) 13940$-13941$.

[15] D. T. Allen e D. R. Shonnard, "Green Engineering - Environmentally Conscious Design of Chemical Processes", Prentice-Hall, 2002.

[16] M. N. Nadagouga e R. S. Varna, "Green and Controlled Synthesis of Gold and Platinum Nanomaterials using Vitamin $\mathrm{B}_{2}$ : Density-assisted Self-assembly of Nanospheres, Wires and Rods", Green Chem. 8 (2006) 516-518.

[17] M. N. Nadagouga e R. S. Varna, "Green Approach to Bulk and Template-free Synthesis of Thermally Stable Reduced Polyaniline Nanofibers for Capacitor Applications", Green Chem. 9 (2007) 632-637.

[18] M. N. Nadagouga e R. S. Varna, "Synthesis of Thermally Stable Carboxymethyl Cellulose/Metal Biodegradable Nanocomposites for Potential Biological Applications", Biomacromolecules 8 (2007) 2762-2767.
[19] M. N. Nadagouga e R. S. Varna, "Green Synthesis of Silver and Palladium Nanoparticles at Room Temperature Using Coffee and Tea Extract", Green Chem. 10 (2008) 859-862.

[20] G. Oberdorster, V. Stone e K. Donaldson, "Toxicology of Nanoparticles: A Historical Perspective", Nanotoxicology 1 (2007) 2-25.

[21] G. Oberdorster, E. Oberdorster e J. Oberdorster, "Nanotoxicology: An Emerging Discipline Evolving from Studies of Ultrafine Particles", Env. Health Perspec. 113 (2005) 823-839.

[22] B. E. Erickson, "Nanomaterial Characterization - Grassroots Effort Aims to Improve Quality of Nanotoxicology Studies", C\&EN 86(50) (2008) 25-26.

[23] Royal Commission on Environmental Pollution (UK), Novel Materials in the Environment: The Case of Nanotechnology, 2008 (em www.rcep.org. uk., acedido em 2009.02.04).

[24] A. Nel, T. Xia L .Madler e N. Li, "Toxic Potential of Materials at the Nanolevel", Science 311 (2006) 622-627.

[25] K. A. D. Guzmán, M. R. Taylor e J. F. Banfield, "Environmental Risks of Nanotechnology: National Nanotechnology Initiative Funding, 2000-2004", Environ. Sci. Technol. 40 (2006) 1401-1407.

[26] A. A. S. C. Machado, "Química e Desenvolvimento Sustentável", BSP Química 95 (2004) 59-67.

[27] A. A. S. C. Machado, "Das Dificuldades da Química Verde aos Segundos Doze Princípios", BSP Química 110 (2008) 33-40.

[28] C. O .Robichaud, D. Tanzil, U. Weilnmann e M. R. Wiesner, "Relative Risk Analysis of Several Manufactured Nanomaterials: An Insurance Industry Context", Environ. Sci. Technol. 39 (2005) 8985-8994.

[29] D. Kushnir e B. A. Sandén, "Energy Requirements of Carbon Nanoparticle Production", J. Ind. Ecol. 12 (2008) 360-375. 


\section{Actualidade Científica}

Novo Processo Químico de Duas EtaPAS PARA TRANSFORMAÇÃo de Biomassa em Biocombustível

Ronald Raines, colaborador dos Departamentos de Bioquímica e de Química da Universidade de Wisconsin-Madison, e o aluno de pós-graduação Joseph Binder, candidato a Doutoramento no Departamento de Química, propuseram um novo processo de transformação de biomassa em biocombustível envolvendo apenas duas etapas.

A característica chave do novo processo está na primeira etapa, onde a celulose é convertida directamente no composto químico 5-hidroximetilfurfural (HMF), intermediário na síntese de uma grande variedade de produtos químicos de grande consumo.

Raines, o responsável pelo projecto, afirma que "outros grupos desenvolveram processos alternativos, demonstrando as diversas etapas necessárias à conversão de biomassa em HMF. No entanto, a síntese final tinha de ser realizada a partir de açúcares simples como a glucose ou a frutose.

A novidade do nosso trabalho consiste na demonstração da possibilidade de resumir a síntese de HMF a apenas uma etapa realizada a partir da própria biomassa sem qualquer manipulação prévia."

Para tornar esta conversão possível, Raines e Binder desenvolveram um novo sistema solvente, uma mistura especial de solventes e aditivos, que aguarda patenteação, com uma capacidade extraordinária para fragmentar a celulose.

Como esta é uma das substâncias orgânicas naturais mais abundantes no planeta, perspectiva-se como uma alternativa promissora aos combustíveis fósseis. Raines acrescenta que "este sistema solvente dissolve bolas de algodão, que são praticamente constituídas por celulose pura, e é relativamente pouco problemático é simples, não é corrosivo, caro ou perigoso."

Esta abordagem ultrapassa outro problema: a lenhina, o ligante que mantém as células vegetais unidas.

As macromoléculas de lenhina envolvem e protegem as moléculas de celulose e são extremamente difíceis de remover. No entanto, Raines e Binder usam no seu sistema moléculas suficientemente pequenas para se difundirem através da estrutura protectora da lenhina e fragmentar a estrutura polimérica da celulose nos seus componentes básicos, que posteriormente podem ser convertidos em HMF.

Assim, na segunda etapa do processo de transformação de biomassa em biocombustível, Raines e Binder convertem o HMF no biocombustível 2,5-dimetilfurano (DMF).

Utilizando celulose de restolho de miIho como biomassa, verificaram que o rendimento global do processo bi-etápico de conversão em biocombustível ronda os $9 \%$.

Raines reconhece que o rendimento obtido ainda não é extraordinário, mas refere que a segunda etapa não está optimizada.

Por outro lado, Raines salienta o potencial do DMF como biocombustível, já que este apresenta um conteúdo energético semelhante ao da gasolina, não é miscível com água e é compatível com as infra-estruturas existentes para combustíveis líquidos de transporte. De facto, o DMF já é actualmente usado como aditivo de gasolina.

Para além do restolho de milho, Raines e Binder testaram o seu método com serradura de pinheiro e pretendem estender a sua aplicação a outras fontes de biomassa.

De facto, a generalidade do processo permite a síntese de DMF ou HMF a partir de qualquer tipo de biomassa.

(adaptado de ScienceDaily www.sciencedaily.com/ releases/2009/02/090210182439. $\mathrm{htm}$, acedido em 20/02/2009)

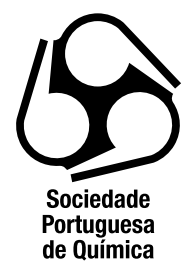

Colabore connosco！

\section{FAÇA PARTE do CONCEITUADO LEQUE DE AUTORES, QUE JÁ ESCREVEU E ESCREVE, PARA O QUÍMICA, E AJUDE-NOS A ENRIQUECER o MUNDO DA QUÍMICA!}

Paulo Brito 